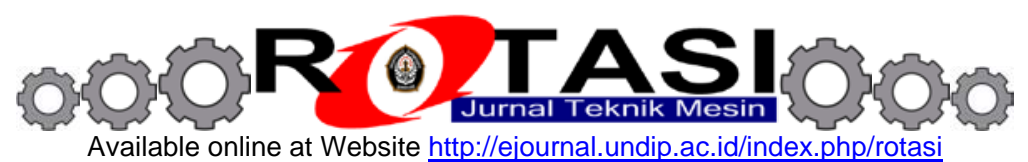

\title{
Polarization Corrosion Test of Austenitic Stainless Steel 316L after High Temperature Gas Nitriding
}

\author{
Agus Suprihanto \\ Departemen Teknik Mesin, Fakultas Teknik, Universitas Diponegoro \\ Jl. Prof. Sudharto, SH Kampus UNDIP Tembalang \\ E-mail: agusm90@yahoo.com
}

\begin{abstract}
Austenitic stainless steel 316L is ones of popular metallic biomaterial for implant due to the good mechanical properties and corrosion resistance. However at corrosion media, highly stressed and oxygen-depleted environment, it still susceptible to corrosion. Various methods have been developed to enhance the corrosion resistance of stainless steel such as high temperature gas nitriding. High temperature gas nitriding for $316 \mathrm{~L}$ has been successfully done. This process is conducted at temperature 1050,1100 and $1200^{\circ} \mathrm{C}$ for 15 and 30 minutes before quenching in the water. Polarization corrosion test showed that the corrosion resistance was significant improved for treatment at temperature $1050^{\circ} \mathrm{C}$ and holding time 15 minutes.
\end{abstract}

Keywords: polarization corrosion test, 316L, high temperature gas nitriding

\section{Introduction}

The first stainless steel utilized for implant fabrication was 18-8. Later 18-8sMo stainless steel was introduced which contains a small percentage of molybdenum to improve the corrosion resistance in chloride solution [1]. This alloy became known as type 316 which has carbon contents $0.08 \%$ (wt). In order to minimize the sensitization and better corrosion resistance, the carbon content is reduce to maximum $0.03 \%$ (wt). This alloy is known as austenitic stainless steel 316L. Austenitic stainless steel 316L is non-magnetic. It cannot be hardened by heat treatments but can be hardened by cold working. A wide range of mechanical properties exists such as softer for annealing conditions or greater strength and hardness for cold working conditions. Selecting of these materials for implant fabrication must be careful because it still susceptible to corrosion under highly stressed and oxygen-depleted environments such as the contacts under the screw of the bone fracture plate [2].

The corrosion process of implants can be done by fretting, crevice and pitting corrosion. The product of corrosion is detrimental to the body which can lead to irritation, allergy and infection [3]. Various methods are developed to enhance the corrosion resistance of 316L such as surface treatments. The well known surface treatments which commonly applies such as surface passivation [4, 5], sandblasting [6, 7], plasma nitriding [8], carbonitriding, etc. The other methods is improved the cleanliness and homogeneity [9]. Special casting process including pressurized electro slag remelting (PSER) in the vacuum conditions in order to enhance the cleanliness and homogeneity. Austenitic stainless steel 316L which fabricated by these special casting process is became known as 316LVM.

Corrosion resistance of 316LVM is significantly enhanced compared to its predecessor 316L due to the excellent micro cleanliness and structural homogeneity [9, 10]. This stainless steel is suitable for the production of both temporary and permanent implants. However, austenitic stainless steel 316LVM is more susceptible to corrosion under body fluid compared to the titanium and titanium alloy [2].

Improvement of the corrosion resistance of stainless steel can be performed by thermo chemical treatment such as nitriding. Nitriding is a process which adds nitrogen atom in the surface of specimens by diffusion. Low temperature nitriding improve both its corrosion resistance and hardness due the formation of thin layer about few micrometer of Sphase [11]. Special surface preparation such as surface activation is needed before nitriding process. Surface activation is used to remove the surface passivity film which act as obstacle diffusion process. Another prospective nitriding process which does not need special surface treatments is high temperature gas nitriding (HTGN) [12].

The principle of HTGN treatments is holding the stainless steel at temperature $1050^{\circ} \mathrm{C}-1200^{\circ} \mathrm{C}$ for certain time in the nitrogen gas atmosphere prior quenching [13]. These treatments produce thicker diffusion depth than low temperature nitriding. Depending on the composition of stainless steel, treatments temperature, holding time and nitrogen gas partial pressure, the microstructure can be modified and the depth of diffusion can be produced. Ferritic stainless steel can be modified in to martensitic or austenitic by HTGN treatments [14]. The corrosion resistance is improved due the increasing of nitrogen contents [15].

Although HTGN treatment for stainless steel has been investigated by many researchers, the comparison of the effect of HTGN treatments on the corrosion behavior for 316L and 316LVM not yet investigated. This paper discusses the corrosion behavior for austenitic stainless steel 316L and 316LVM after short duration of HTGN treatments. 


\section{Material and experiment methods}

Specimens were prepared from $2 \mathrm{~mm}$ thick plate of 316L and $4 \mathrm{~mm}$ thick plate of austenitic stainless steel 316LVM. The chemical compositions of the specimens are shown in table 1. Specimens were rinsed using ultrasonic cleaner in acetone as soaking medium prior HTGN treatments in order to remove oil and debris. HTGN treatments was carried out at modified three zone heating chamber of vertical furnace (Carbolite ${ }^{\circledR}$ type TZF 15/50/610) which equipped with a precision digital pressure controller.

Table 1. Chemical composition (\%wt)

\begin{tabular}{cccccccc}
\hline & $\mathrm{C}$ & $\mathrm{Cr}$ & $\mathrm{Ni}$ & $\mathrm{Mo}$ & $\mathrm{Mn}$ & $\mathrm{Si}$ & $\mathrm{Fe}$ \\
\hline $316 \mathrm{~L}$ & 0.01 & 15.5 & 11.8 & 1.24 & 1.23 & 0.47 & balance \\
\hline
\end{tabular}

Specimens were inserted to the furnace tube, vacuumed to $10 \mathrm{~Pa}$ for 15 minutes. Flushing valve opened and the tube flushed using nitrogen gas at $1000 \mathrm{ml} / \mathrm{min}$ for 15 minutes prior heated. Nitrogen gas flowed continuously at 100 $\mathrm{ml} / \mathrm{min}$ until treatment temperatures achieved and flushing valve then closed. The temperature treatment was chosen at 1050,1100 and $1200^{\circ} \mathrm{C}$. The nitrogen gas pressure maintained at $0.3 \mathrm{~atm}$. using precision digital gas pressure controller equipment. If the gas pressure increased above $0.3 \mathrm{~atm}$., the controller opened the solenoid valve automatically and reduced the gas pressure back to $0.3 \mathrm{~atm}$. The holding time was chosen for 15 and 30 minutes. After heating process, specimens quenched in the water by opened the bottom side of tube and quick release mechanism.

As received and treated specimens were cut and machined to produce $1.4 \mathrm{~mm}$ disc. The discs were gently polished in order to remove the scale using metal polish. These discs produced $1 \mathrm{~cm}^{2}$ area in the corrosion test. The discs were rinsed by acetone prior corrosion test. The corrosion test was carried out at the surface of disc using polarizations resistance corrosion techniques in ringer solution as corrosion medium at temperature $37^{\circ} \mathrm{C}$. For the first running test, the initial potential test and final was selected $-20 \mathrm{mV}$ vs $E_{\text {corr }}$ and $+20 \mathrm{mV}$ vs SCE respectively and the potential scan rate was $0.1 \mathrm{mV}$.

\section{Results and discussions}

The effect of treatments temperature of HTGN process for 15 minutes holding time on the corrosion of 316L is shown in Fig.1. The curve is shifted to the left and up compared to the as-received sample. $E_{\text {corr }}$ for treated sample increase after treatments. It indicates that the treated sample is better corrosion resistance compared to the as-received. The corrosion resistance of treated sample increases due to the diffusion of nitrogen in to the sample.

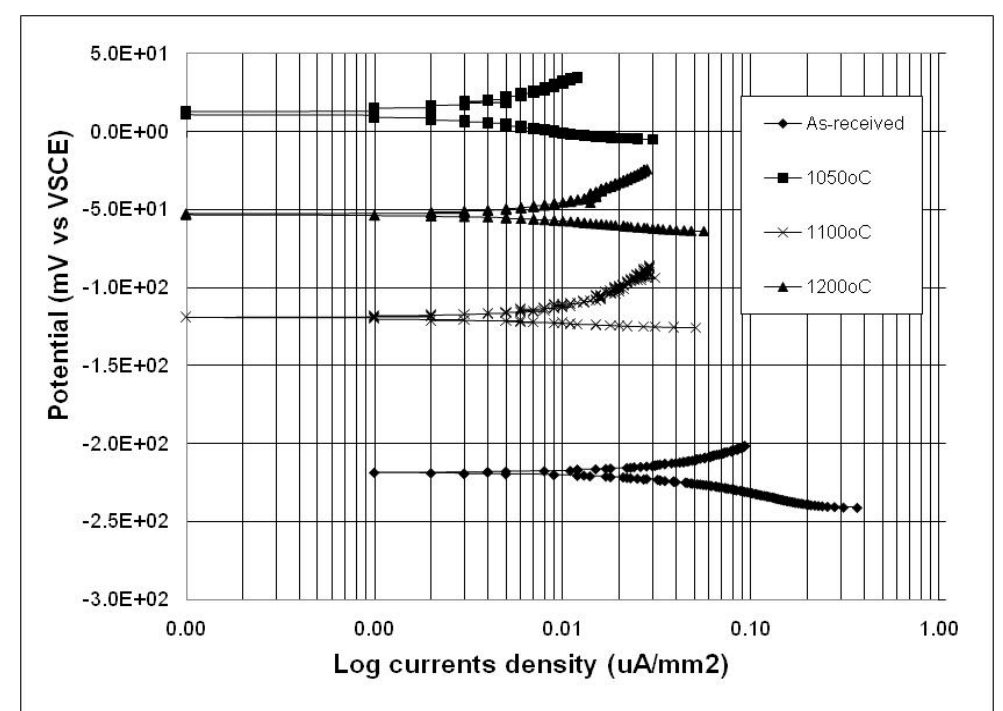

Figure 1. Polarization resistance curve for 15 minutes holding time

Fig. 2 shows the effect of 30 minutes holding time on the corrosion resistance for 316L. Treated sample at $1050^{\circ} \mathrm{C}$ has higher corrosion resistance compared to the others. This result is identical to the 15 minute holding time. The highest corrosion resistance is achieved at treatments temperature at 1050 followed by 1200 and $1100^{\circ} \mathrm{C}$. The corrosion curve for treatments temperature at $1200^{\circ} \mathrm{C}$ is close to the corrosion curve of treatment temperature at $1050^{\circ} \mathrm{C}$. It indicates that for 30 minutes holding time, the corrosion resistance for treated sample at $1050^{\circ} \mathrm{C}$ is identical to the treated sample at $1200^{\circ} \mathrm{C}$. 


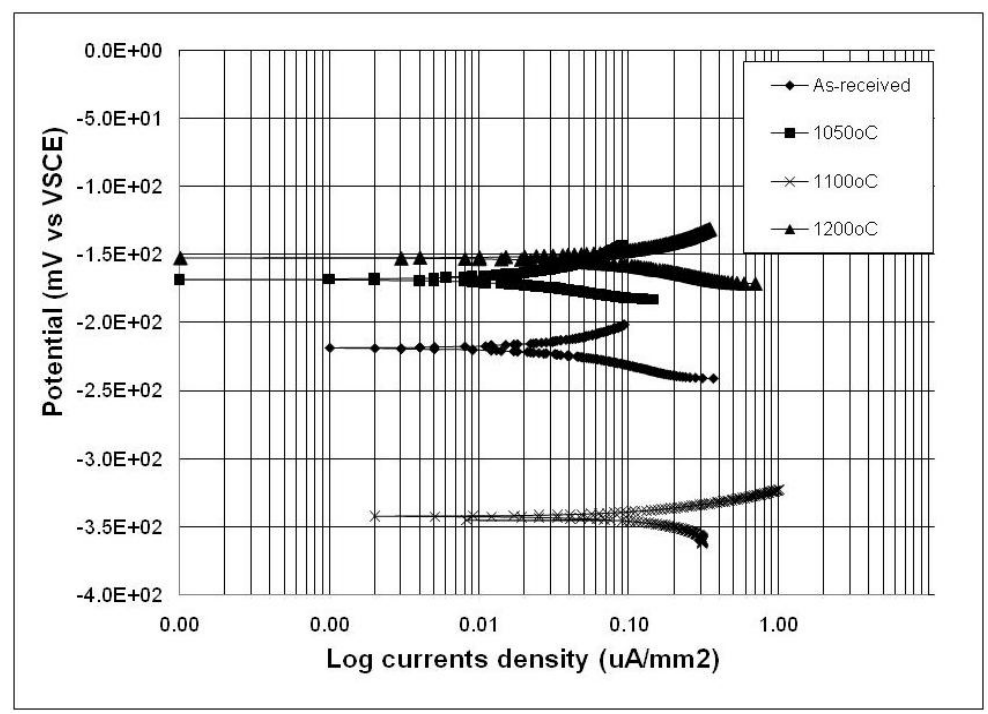

Figure 2. Polarization resistance curve for 30 minutes holding time

Fig. 3 shows the corrosion curve for 15 and 30 minutes holding time and treatment temperature at $1050^{\circ} \mathrm{C}$ and $1200^{\circ} \mathrm{C}$. The corrosion resistance for 30 minute holding time is less than 15 minutes holding time for all treatments temperature. The short holding time and lower treatment temperature produce the highest corrosion resistance. This fact showed that the best corrosion improvement for 316L is achieved at 15 minutes holding time and treatment temperature at $1050^{\circ} \mathrm{C}$.

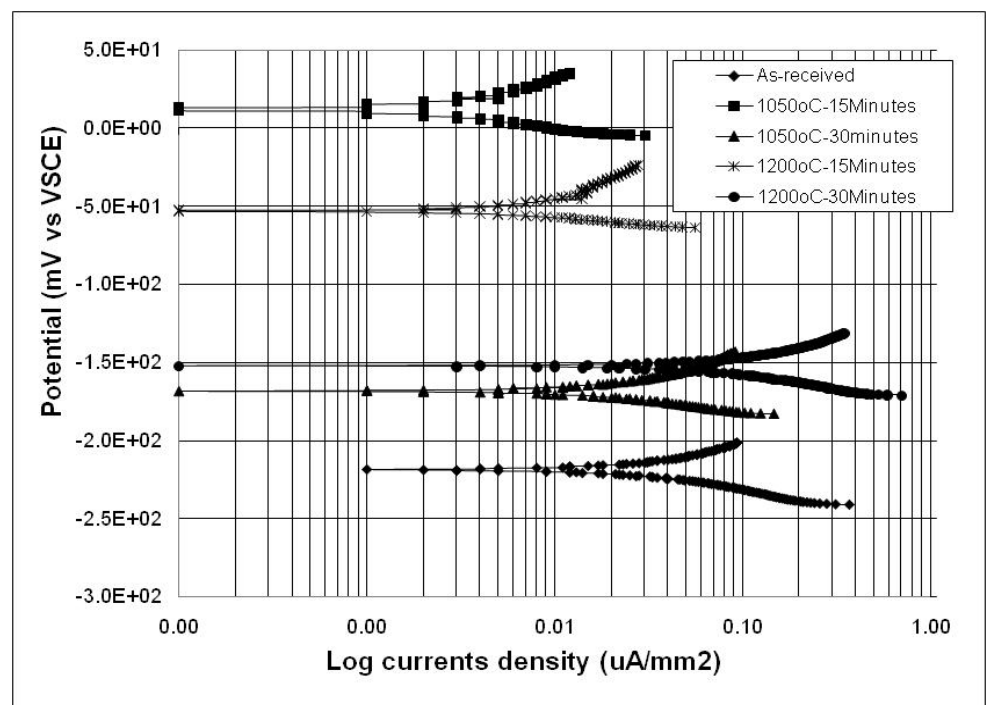

Figure 3. Polarization resistance curve for 15 and 30 minutes holding time and treatment temperature 1050 and $1200^{\circ} \mathrm{C}$

The effect of nitrogen on the corrosion resistance of stainless steel can be predicted using pitting resistance equivalent number (PREN). The formula of PREN is \%Cr $+3.3 \% \mathrm{Mo}+(10-30) \% \mathrm{~N}$. Corrosion resistance of stainless steels increases with PREN. PREN formula shows that nitrogen is more effective to enhance the corrosion resistance of stainless steel.

HTGN treatment is thermo chemical process which adds nitrogen atoms by diffusion process. The amount of nitrogen atoms diffused in to sample depends on the chemical composition of stainless steel, nitrogen partial gas pressure, treatments temperature and holding time $[12,14]$. The higher treatments temperature and longer holding time results more nitrogen atoms diffused in to sample, raises the magnitude of PREN and increases the corrosion resistance. Despite increasing treatments temperature results more nitrogen atom diffused in to sample, the corrosion resistance of 316L does not increase too. It shows from Fig. 2, the corrosion resistance of treated sample at $1050^{\circ} \mathrm{C}$ is higher than at $1100^{\circ} \mathrm{C}$. However, the corrosion resistance of $316 \mathrm{LVM}$ after HTGN treatments is identical for all treatments temperature.

Corrosion is the process releasing metal ion which occurs at the surface. The corrosion resistance of the sample depends on the surface passive film and its stability. Corrosion occurs if the surface passive film is broken. Strong and 
stable surface film produce higher corrosion resistance of materials. Because corrosion depends on the conditions at the surface, the effect of diffusion depth does not significant to the corrosion process. Despite longer holding time and higher treatments temperature in HTGN produces more diffusion depth, the nitrogen contents at the surface probably close to the solubility limit.

The nitrogen atom which diffused in to sample is from dissociation process of nitrogen gas molecules at the surface due to the present of Fe which acts as catalyst. Nitrogen atoms then diffuse at the surface. It produce that the concentration of nitrogen atoms at the surface for short holding time is higher than at the region below the surface. It can be assumed that the diffusion rate of nitrogen in the sample is slower than at the surface. Furthermore, the concentrations of nitrogen at the surface reach its solubility limits. Increasing holding time and treatments temperature do not increase the nitrogen contents at the surface, but it increase the concentration of nitrogen in the region below the surface.

The solubility of nitrogen in the stainless steel decreases with temperature [14]. The higher solubility is obtained at $1050^{\circ} \mathrm{C}$ than 1100 and $1200^{\circ} \mathrm{C}$. Thus, the highest magnitude of PREN and the corrosion resistance are achieved at treatments temperature $1050^{\circ} \mathrm{C}$. The effects of solubility limit at the sample explain why the highest corrosion resistance is obtained at 15 minutes holding time and treatments temperature at $1050^{\circ} \mathrm{C}$.

\section{Conclusion}

HTGN treatment enhances the corrosion rate of austenitic stainless steel 316L. The corrosion curve after HTGN treatments is shifted to the left and up which indicates that corrosion resistance increases after treatments. The highest corrosion resistance is obtained at 15 minutes holding time and treatment temperature at $1050^{\circ} \mathrm{C}$.

\section{References}

1. Park, J.B., Kim, Y.K., 2003, Metallic Biomaterials, Edited by: JB Park, and JD Bronzino, Biomaterials: Principles and Applications, CRC Press, Florida, pp. 1-20

2. Desai, S., Bidanda, B., Bartolo, P., 2008, Metallic and Ceramic Biomaterials: Current and Future Developments, Edited by: P Bartolo and B Bidanda, Bio-Materials and Prototyping Application in Medicine, Springer, New York, pp. 1-14

3. Yang, K., Ren, Y., 2010, Sci. Technol. Adv. Mater., Vol. 11(1), pp. 1-13

4. Bidhendi, H.R.A., Pouranvari, 2011, Metalurgija, Vol. 17(1), pp. 13-22

5. Shahryari, A., Omanovic, S., 2007, Thin Solid Films, Vol. 515(1), pp. 4727-4737

6. Multigner, M., Frutos, E., Gonzales, Carrasco, J.L., Jimenez, J.A., Marin, P., Ibanez, J., 2009, Mater. Sci. Eng.: C, Vol. 29(4), pp. 1357-1360

7. Suyitno, Arifiyanto, B., Widodo, T.D., Mahardika, M., Dewo, P., Salim, U.A., 2012, Int. J. Min. Metall.Mater, Vol. 19(12), pp. 1093-1099

8. Rahman, M., Haider, J., Hashmi, M.S.J., 2005, Surf. Coat. Technol., Vol. 200(5-6), pp. 1645-1651

9. Ahmadi, S., Arabi, H., Shokuhfar, A., Rezer, A., 2009, J. Mater. Sci. Technol., Vol. 25(5), pp. $592-596$

10. Talha, M., Behera, C.K., Sinha, O.P., 2012, J. Chem. Pharma. Res., Vol. 4(1), pp. 203-208

11. Buhagiar, J., Bell, T., Sammons, R., Dong, H., 2011, J. Mater Sci Mater Med, Vol. 22(5), pp. 1269-1278

12. Berns, H., 2007, Mater. Sci. Heat Treat., 49(11-12); 578-580

13. Berns, H., Siebert, S., 1996, ISIJ Int., Vol. 36(7), pp. 927-931

14. Tschiptschin, A.P., 2002, Mater. Res., Vol. 5(3), pp. 257-262

15. Bayoumi, F.M., Ghanem, W.A., 2005, Mater. Let., Vol. 59, pp. 3311-3314 